\title{
Research and Analysis on the Value of Customer Satisfaction in the Environmental Space of the Museums_- The case of the Xiamen Museum
}

\author{
Qiduan Chen ${ }^{1, a}$, Ying Liu ${ }^{2, b}$ \\ ${ }^{1}$ Department of Art and Design, The Jimei university, Jimei, Xiamen,Fujian, China \\ ${ }^{2}$ Department of Art and Design, The Jimei university, Jimei , Xiamen,Fujian, China \\ a1140751800@qq.com \\ b*646510932@qq.com
}

\begin{abstract}
With the development of economy, modern museums are facing competition from many different leisure activities and entertainment venues. For sustainable operation, museums, which are nonprofit organizations, also must think about how to provide quality service and satisfy visitors. However, there is relatively little research on how the museum can develop a positive space dialogue through environmental space as well as develop new forms of environmental space to improve visitors' satisfaction. This research takes Xiemen Museum, which is now developing a new environmental space design, as a study case. On the basis of the relevant theory of environmental space design, it analyses the latest customer satisfaction research in museums both at home and abroad, and divides the literature about customer satisfaction according to four aspects: 1) directly embody the features of environmental space, the service nature of environmental space; 2) interactivity between environmental space and customers; 3) indirectly embody customer satisfaction in environmental space of the museums and influencing factors; and 4) understanding the process and connotation of the environmental space design of the museum in an attempt to construct a value-creation structure for customer satisfaction. Finally, this research develops strategies for improving customer satisfaction as a reference for museum management.
\end{abstract}

Keywords: museum, environmental space design, customer satisfaction, factor of influence

\section{INTRODUCTION}

Traditional museums are gradually unable to meet the needs of visitors due to the rapid economical development in China. In recent years, an increasing number of museum operators start paying attention to environmental space design of museums, so as to enhance their competitive advantages and satisfy tourists' expectations by better services. In 2008, the Publicity Department of the Communist, the Ministry of Finance, the Ministry of Culture and the State Administration of Cultural Relics co-issued a notification, requesting free admission of all the public museums, memorial halls and the like under administration of nationwide cultural relic departments. Till the end of 2019, free admission is executed by 4,929 museums in China, with as many as 1 billion customers received every year. The free admission to museums has brought unprecedented challenges to development of museums. Secondly, the museums are facing competition from various recreation activities and entertainment venues. However, environmental space and facilities in most Chinese museums are out of date, so they often fail to provide unique experience to visitors or satisfy customers. The low customer satisfaction degree will influence the customers' desire for re-visiting and thus influence overall benefits of museums. Therefore, it is of crucial necessity to explore influential factors over customer satisfaction degree towards the environmental space of museums. With Xiamen Museum under development of the environmental space design as the case, the research focuses on environmental space of museums, and analyzes influential factors over the museum customer satisfaction degree, so as to propose strategies targeted at improving the customer satisfaction. 


\section{CORRELATED STUDIES}

In this study, a comprehensive inquiry has been made into what effect the physical environment of museums has had upon visitors' satisfaction.

\subsection{Correlated Studies on Museum Environmental Space Design}

As believed by Li Qingchen (2013), visitors have a complicated psychological course while appreciating exhibitions in museums, while exhibition activities and their psychological activities influence and interact with each other. While appreciating the exhibitions, the audiences will generate different psychological activities due to influences of different factors, such as nationality, religion, culture, territory and customers. During the flowing course, audiences are influenced by the space environment in an exhibition hall. The flowing activities of audiences in a museum are also taken into account in space environment design, so as to let audiences feel and cognize the space. Space changes can greatly mobilize audiences' interest and imagination and create a good psychological environment for people to receive information. In the field of museum design, designers can induce audiences by design of the space environment, so as to better satisfy audiences' psychologies by the museum space environment [1]. In A Study on Museum 3 Rest A Tea in Korea and Japan by Seul-A Jo. Ko Jeong-Min, it was found in the investigation over National Museum of Contemporary Arts of South Korea and National Museum of Tokyo, Japan that a rationally designed visiting path could effectively relieve visitors' "museum fatigue". Visitors' satisfaction is directly influenced by surroundings of museum buildings, while it is directly influenced by the indoor exhibition environment [2]. As pointed out by Ding Dichen (2018), because of existence of own history and culture of a museum, emotional information needs to be provided to browsers and interactions on the mental level are also needed, so that visitors can communicate and talk with the history in different space environments of the building and obtain experience surpassing the visiting [3]. In environmental space of museums, the diversified environmental atmosphere and spatial forms can bring abundant experience for people, so as to attract more visitors.

\subsection{Related Studies on Customer Satisfaction Degree}

As the customer satisfaction theory has drawn more and more attention, a lot of scholars have studied the customer satisfaction degree, and the concepts and cognition over the customer satisfaction degree have been updated continuously (see Table 1). As early as the earlier stage of 1960s, Cardozo (1965), an American scholar, proposed the concept of satisfaction degree and made empirical research on it [4]. According to the contrast theory he proposed, if a consumer feels the difference between product performance and expectation, he/she will feel unsatisfied if the product performance cannot reach his/her expectation; if they conform to each other or his/her expectation is exceeded, satisfaction will be generated. As believed by Howard (1969), the customer satisfaction degree refers to a customer'scognitive state about whether what he/she pays is suitable for what he/she gains. [5] As argued by Hutt (1977), the customer satisfaction degree is "the customer's feeling towards a consumption experience and the overall evaluation of purchase products or services and the emotional reflection generated after comparison over his/her values" [6]. As proposed by Mano \& Oliver (1993), the customer satisfaction degree means the subjective feeling and emotional responses of a customer during product use [7]. In the ISO/DIS 9000 of 2000 version, the customer satisfaction degree is defined as a customer's opinion towards the degree for a matter to satisfy his/her demands and expectations. The matter refers to a specific event in specific time based on mutual demands and expectations and communications of related parties over this [8].

Table 1 .Summary table of studies on customer satisfaction degree

\begin{tabular}{|c|c|c|}
\hline Time & Scholar & Definition \\
\hline 1965 & Cardozo & $\begin{array}{l}\text { The customer satisfaction degree can increase } \\
\text { re-purchase behaviors of customers and further } \\
\text { influence purchase of other products. }\end{array}$ \\
\hline 1969 & Howard & $\begin{array}{l}\text { The customer satisfaction degree refers to a } \\
\text { customer's cognitive state about whether what } \\
\text { he/she pays is suitable for what he/she gains. }\end{array}$ \\
\hline 1977 & Hutt & $\begin{array}{l}\text { It is the customer's feeling about a consumption } \\
\text { experience as well as the overall evaluation of } \\
\text { products or services purchased and emotional } \\
\text { reflection after comparison over values. }\end{array}$ \\
\hline 1982 & $\begin{array}{c}\text { Churchill and } \\
\text { Suprenant }\end{array}$ & $\begin{array}{l}\text { It is a result generated from purchase and use } \\
\text { of products, and from the purchaser's } \\
\text { comparison of the expected remuneration and } \\
\text { the invested cost. }\end{array}$ \\
\hline 1985 & $\begin{array}{l}\text { Parasuraman, Zei } \\
\text { thaml \& Berry }\end{array}$ & $\begin{array}{l}\text { The satisfaction degree means the } \\
\text { psychological and emotional situation of an } \\
\text { individual after experiencing something. It is a } \\
\text { type of attitude, intention or demand generated } \\
\text { under influences of social factors and } \\
\text { psychological conditions, or it is influenced by } \\
\text { external factors such as atmosphere and } \\
\text { collective interactions, etc. }\end{array}$ \\
\hline 1992 & Fornell & $\begin{array}{l}\text { The customer satisfaction degree is an overall } \\
\text { feeling which can be evaluated directly. A } \\
\text { consumer will compare a product or service } \\
\text { with his/her ideal standards. It will be possible } \\
\text { that the consumer is satisfied with the product } \\
\text { or product at the very beginning, but deems it to } \\
\text { be ordinary after comparing it with the original } \\
\text { expectation. }\end{array}$ \\
\hline 1993 & Mano \& Oliver & $\begin{array}{l}\text { It is the customer's feeling towards a } \\
\text { consumption experience, and also the overall } \\
\text { evaluation of the product or service purchased } \\
\text { and emotional reflection after the comparison } \\
\text { over values. }\end{array}$ \\
\hline
\end{tabular}




\begin{tabular}{|c|l|l|}
\hline 2002 & Yeung & $\begin{array}{l}\text { As believed, the customer satisfaction can be } \\
\text { deemed as a type of authentication of customer } \\
\text { expectations and has nearly been } \\
\text { conceptualized into the threshold of customers' } \\
\text { satisfaction with services. }\end{array}$ \\
\hline
\end{tabular}

\subsection{Correlated Studies on Museum Customer Satisfaction Degree}

G. T. Fechner (1897) from Germany took the initiative to study audiences of museums. Since 1980s, the research on museum audiences gradually became a hot topic in western countries. As believed by Frans Schoutent [9], the most necessary measure for museums to improve the audience satisfaction degree is to realize "joyful" supply. Museum must be systematically designed and connected for audience satisfaction based on expected quality, sensed quality and sensed value by investigating the antecedents and consequences of audience satisfaction[10]. Yu Jia (2010) studied the Xuzhou Museum and used the comprehensive evaluation index system to divide the overall satisfaction degree towards the museum into four factor layers: tourist attraction, image accessibility, comprehensive service management and hardware facility environment.

\section{VALUE EXPLORATION OF CUSTOMER SATISFACTION WITH TOWARDS ENVIRONMENTAL SPACE OF XIAMEN MUSEUM}

With Xiamen Museum as the case, the paper based on the development status quo of it and analyzes influential factors of its customer satisfaction degree from the four aspects, including feature, services, customer interactivity and social contribution of the environmental space of Xiamen Museum.

\subsection{Development Status Quo of Xiamen Museum}

As a local comprehensive museum, Xiamen Museum was put into construction in 1983 and opened to the public formally in 1988, with the formal location in Bagua Building of Gulangyu Island. In June 2006, as approved by the Organization Establishment Committee of the CPC Xiamen Municipal Party Committee, Zheng Chenggong Memorial Hall and Xiamen Cultural Heritage Protection Center in Xiamen were incorporated into Xiamen Museum which now consists of 7 parts: host hall of Xiamen Museum, Zheng Chenggong Memorial Hall, Xiamen Special Economic Zone Memorial Hall, Xiamen Cultural Heritage Protection Center, Siming Prison Rescue Struggle Exhibition Hall, Chen Huacheng Memorial Hall and Chen Shengyuan Former Residence. In 2007, the new museum was relocated to Xiamen Culture and History Center at
No.95, Sports Road, Siming District, Xiamen, with the floor area of 25,300 square meters, the exhibition hall covering 9597 square meters and the warehouse area of 2800 square meters. The new museum is expanded by 6 times compared with the former. The new Xiamen Museum was opened to the public formally in 2008. It is also dedicated to collection, protection, research and display of precious cultural relic of Fujian, Taiwan and those handed down from ancient times. By virtue of the visualized exhibits, the museum manages to propagandize cultural relic policies and knowledge, carry forward traditional Chinese culture and realize education in patriotism. At present, it has collected nearly 20,000 cultural relics, including 3,983 over level 3 cultural relics authenticated. Four halls are formally opened to the public in Xiamen Museum, themed by Display of Local History of Xiamen, Prospect Garden of Ancient Stone Sculptures of Fujian and Taiwan, Folk Custom Cultural Relic Display of Fujian and Taiwan and Boutique Display of Collection Cultural Relics, respectively.

\subsection{Analysis of Influential Factors on Customer Satisfaction Degree with Environmental Space of Xiamen Museum}

\subsubsection{Features of Environmental Space of Xiamen Museum}

In China with a long history, different regions boast the diversity in historic culture. With unique local features, Xiamen gives a full presentation of southern Fujian culture. Influenced by the local culture, Xiamen Museum adopts display and design modes which can highlight local features in its environmental space design. A typical case is the "Fujian and Taiwan Folk Customs" display exhibition (see Fig. 2).

"Fujian and Taiwan Folk Customs" exhibition is themed by folk customers in Fujian and Taiwan and mainly aims to present the folk custom phenomena in southern Fujian in the hall covering an area of over 2,000 square meters. It shows the folk and custom life of Fujian and Taiwan, with striking characteristics. The display space design of the exhibition is original and creative, wherein the seasons, festivals and customs of southern Fujian people during the 363 days (1 year) are taken as the main framework. The exhibition contents are divided into introduction lobby, spring, summer, autumn and winter. The introduction lobby shows the wood sculptures of main festival customs in spring, summer, autumn and winter. The themed display space is the visiting key for visitors. Thanks to the "Fujian and Taiwan Folk Customs" exhibition in Xiamen Museum, living scenes of southern Fujian people are shown, and a real sense of environmental space has been created. Local customs and traditions are set off by contrast through use of colors and treatment of tones in the 
environmental design, so that the southern Fujian culture with unique features is shown to the audiences. While visiting the museum, customers expect to know more about local featured culture by the exhibition and decide whether they will go on with the visiting according to such experience. Therefore, the features of space design can influence customers' visiting willingness and thus affect their satisfaction degree.

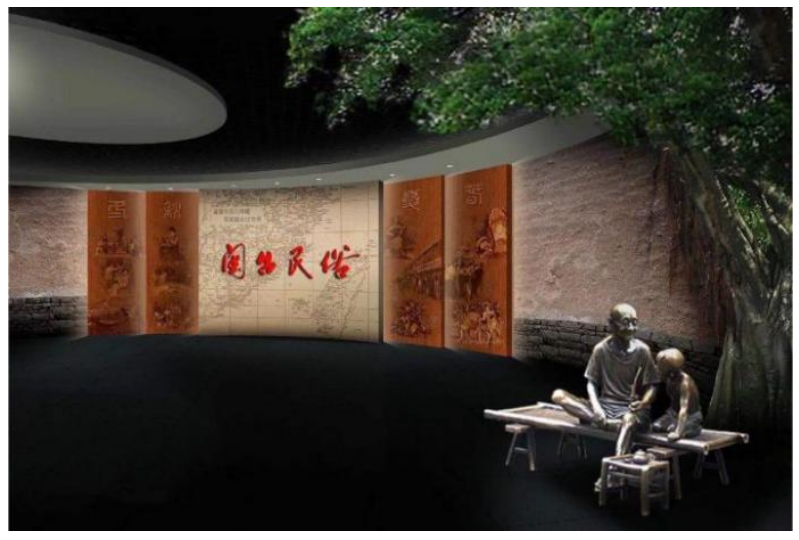

Figure 1 Fujian and Taiwan Folk Custom Display

\subsubsection{Service of Environmental Space of Xiamen Museum}

Getting rid of the education function of traditional museums, Xiamen Museum adds the self-help voice explanation service in the exhibition hall, by which visitors can use a mobile phone to scan the QR code beside exhibits to browse the exhibit information. A touch screen at the entrance of exhibition areas enables the audiences to click and browse, which can provide a guidance service for those visitors who are going to enter the main display space. Museum is a type of social public space, while its service is transformed from relatively singular ones to a diversified service function. The transformation of space service functions means that the environmental space design of the museum is also changing towards diversification, so as to improve the service benefits. The service function of a museum decides its space environment layout. Setting of the museum space environment can also influence customers' perception of the museum service quality, so as to influence customers' satisfaction degree. Therefore, users' satisfaction degree can be effectively improved if enough attention can be paid to the service function of museum environmental space.

\subsubsection{Interactions between Environmental Space of Xiamen Museum and Customers}

The landscape scenes of Xiamen Museum have open scenery and far-reaching scenes, creating a sense of immediacy. Audiences can get access to or step into scenes at a short distance, so as to experience it in person. The visitor's simple action of stepping into the traditional residence looks like that he/she enters the real life of southern Fujian people. In the teahouse scene of the "Fujian and Taiwan Folk Customs" exhibition, visitors can enter it via the entrance and experience the recreational life of southern Fujian people who like drinking tea while watching dramas thanks to the tea sets on the table and the endless traditional Chinese operas being played. Due to the own history and culture of the museum, it is necessary to provide emotional information to visitors and generate interactions on the mental level, so as to let them communicate and talk with the history in the different environmental space and obtain the experience surpassing the visiting itself. Their satisfaction degree will be changed when their experience surpasses the expectation, so that their loyalty towards the museum will be influenced.

\subsubsection{Social Contribution of Environmental Space of Xiamen Museum}

More than places dedicated for protecting precious cultural relics, modern museums also serve as a place for studying profound cultural deposits. To some extent, museums have a social education function besides the social responsibility it assumes. The environmental and space design of Xiamen Museum effectively shows the image features of southern Fujian as well as local historical traditions and artistic results. In Xiamen Museum, visitors can see the historical miniatures and civilization development of Xiamen. By effectively gathering the southern Xiamen cultures, Xiamen Museum manages to maintain the diversity in southern Fujian culture and promote inheritance of culture in Xiamen.

Carrying and inheriting culture, museums remain a symbolic form of modernized urban construction. Museums exert important effects on visitors by virtue of specific environmental space design and exhibition modes. Only by fully showing local culture of a region, a museum can let visitors know about the city and link both more closely, thereby establishing a good museum image and indirectly increasing the visitors' satisfaction degree.

\section{SUGGESTIONS CONCERNING MUSEUM CUSTOMER SATISFACTION DEGREE}

Under the intense market competition at present, it is necessary for non-profit museums to know about customers' subjective demands, pay attention to their experience values and improve services from the perspective of customers, so as to obtain the continuous competitive advantages. Based on the above analysis over influential factors of museum customer satisfaction degree from the perspective of museum environmental space design, the paper proposes relevant suggestions 
for improving the museum customer satisfaction degree from the following four aspects.

\subsection{Emphasis on Service Layout of Environmental Space}

Aiming at visitors of different social statuses and ages, museums should satisfy their diversified demands. It is feasible for museums to provide creative space services and supply customers with space and places of diversified and creative cultural communications. The environmental space layout of museums should take into account design aesthetics besides the abundant and diversified space service demands. Spatial independence and user demands should be considered during design.

\subsection{Emphasis of Internal Open Design of Environmental Space}

New forms of museum environmental space are needed for social development. The paper explores factors influencing museum customer satisfaction degrees from the perspective of environmental space. Operators of museums should pay attention to factors such as feature, interaction and service in museum environmental space design, so as to improve visitors' experience and thus improve customers' satisfaction degree and loyalty.

\subsection{Focus on Customers' Sense Experience}

With the rapid development of economy, more and more people choose to visit museums, so as to sense the diversity and charm of art, science and history in the specific environmental space. Hence, museums should pay attention to visitors' sense experience and make flexible use of elements such as shape, light and colors in display of the museum environmental space, so as to make the internal beauty stand out. In this way, museums can convey the targeted information comprehensively and realize traditional culture re-education of visitors in a short time. More people will understand the profound connotations of museum culture, thereby improving their satisfaction.

\section{CONCLUSION}

To sum up, customers will always feel satisfied when features, services and interactions they experience in the museum environmental space are beyond the expectation; on the contrary, if their expectation for the museum environmental space is not reached, they will feel unsatisfied. As found in the research analysis, the museum environmental space influences customers' satisfaction degree. Specifically, the more attractive the environmental space carrying local features is, the higher the satisfaction with software services will be.
Therefore, operators of museums should focus on construction of museum environmental space, so as to promote development of new forms of museums.

\section{REFERENCES}

[1] Li Qingchen. On the psychology of audience behavior and the design of museum space. The northern literature, 2013.

[2] Seul-A Jo. Jeong-Min Ko. A Study on Museums Rest Area in Korea and $\mathrm{J}-\operatorname{apan}[\mathrm{J}]$. Journal of the Korea Conten - ts Association. 2016.

[3] Ding Dichen - Research on the Design of Museum Space Environment Based on Experiential Psychology. Building Materials Development Orientation. 2018.

[4] CardozoRM. An Experimental Study ofConsumer, Ex - peetationandSatisfaction[J] . Journalof MarketingRe-search, 1965, (2): 244-249.

[5] Howard, John A. Jagdish N. Sheth. The Theory of Buyer Behavior[J]. New York Wiley, 1969: 27. 28

[6] Lempel, Donald J. Consumer Satisfaction wim the Home Buy Process: Conceptualization and MeasuDeIlt . [J]Cdge , Marketing Science Illstitute, 1977: 7-9.

[7] Haim M, Oliver RL . Assessing the Di mensionality and Structure of the Consumption Experience: Evaluation, Feeling, and Satisfaction [J]. Journal of Consumer Research, 1993, (3): $451 \sim 466$.

[8] Liu Linglin - Customer satisfaction analysis and debugging [N]. China Enterprise News. $7 \sim 19$.

[9] Frans Schouten. Improving visitor care in heritage attractions $[\mathrm{J}]$. 1995(4).

[10] Liao Hong , Wang Heng - A Study on Audience Satisfaction [J]. The Chinese Museum., 2001, 4 